\title{
Everyday consumption practices as a site for activism? Exploring the motivations of grassroots reuse groups
}

\author{
Mike Foden* \\ CRESR, Sheffield Hallam University
}

\begin{abstract}
This paper draws on early findings from a study of grassroots groups and individuals engaged in alternative consumption practices: ways of acquiring, exchanging, using and disposing of goods outside of the formal economy. The study focuses on individuals and groups that take items that would otherwise be classed as waste and try to put them (back) to use. It is especially concerned with ethical and political dimensions of these practices: how small day-to-day acts are associated with trying to live according to a set of values and how they might make a difference to wider problems. Two existing ways of theorising the connection between everyday individual acts and social change are put forward: prefigurative politics and political consumerism. Initial findings suggest ambivalence concerning the political nature of such activities, with participants recognising a politics of consumption, but hesitant to describe their engagement in alternative consumption practices as a political act.
\end{abstract}

Keywords: consumption, activism, consumer society, waste.

\section{Introduction}

This paper presents initial findings from a study on alternative consumption practices. By 'consumption practices' I mean ways of acquiring, using, exchanging or disposing of goods. By 'alternative' I mean that they operate to some extent outside of the mainstream or formal economy. More specifically my research focuses on individuals and groups that find value in items that would otherwise be classed as waste and try to put those items (back) to use. For the purposes of this paper I will refer to these as 'reuse groups'.1

While previous studies have provided insightful evidence on the degree to which informal and second-hand forms of exchange are chosen or a necessity (e.g. Williams and Paddock, 2003; Williams, 2003; Williams and Windebank, 2005), this study is especially concerned with ethical and political dimensions of alternative consumption practices: how small day-to-day acts of opting out of the market might be associated with trying to live according to a set of values or making a difference to wider social and 
p. 149. Everyday consumption practices as a site for activism? Exploring the motivations of grassroots reuse groups

environmental problems. As will become clear, many participants engage in reuse activities out of a concern for social justice and, even more so, as an attempt to live less environmentally-destructive, or more sustainable, lives.

After briefly setting out the conceptual origins of the study, I will go on to discuss two distinct understandings of the everyday as a space for political participation: prefigurative politics and political consumerism. I will then present some emerging findings, concentrating specifically on the question of why people engage in alternative consumption practices, as well as what they hope this will ultimately achieve, if anything.

\section{Activism in a consumer society}

The present study emerged from an interest in the idea, prevalent in both social theory and popular culture, that 'Western societies are increasingly consumer societies' (Clarke, 2003: 2, original emphasis). Typically the term 'consumer society' calls to mind some combination of individualism and the insatiable pursuit of novel experiences, along with corresponding social and environmental problems, including new forms of social inequalities and a 'throwaway' economy reliant on excess and waste (Bauman, 2005; 2008). Despite its widespread use, however, there is no consensus on how a consumer society is defined - what sets it apart from what came before - or at what point in time the imagined transition to a consumer society was made. While for some this emergence is equated with a broadening of the consumption base (see, for example, McKendrick, 1982), it was a different sense of the consumer society that formed the starting point for this research: a society which 'engages its members primarily in their capacity as consumers' (Bauman, 2000: 76); one in which we are 'increasingly consumers first and foremost ... and our principal duty is to consume' (Clarke et al., 2003: 274, original emphasis). Moreover, it is the systemic role which consumption plays in the reproduction of capitalism which is said to set apart today's consumer society: 'Consumption is no longer just one aspect of society amongst others. In a fully fledged consumer society, consumption performs a role that keeps the entire social system ticking over' (Clarke, 2003: 13). Ritzer and Slater (2001: 6) highlight links between this particular view of the consumer society and a series of 'modernization processes', culminating in the neoliberal political projects of the 1980 s onwards. The provision of core services and the democratic process itself have been redefined 'according to the paradigm of consumption', as 'private, market-based choice has become increasingly central to social life' and 'key social values, identities and processes are negotiated through the figure of "the consumer"' (p.6).

More specifically, this study began with an interest in exploring the nature of activism within this context and the twin role of consumption in both the type of social and environmental problems identified and the actions employed in response to them. If social life is increasingly organised around and enacted through consumption, does this include the ways in which people engage in political action? In other words, has activism become a matter of market-based choice? Are long-standing, other-oriented, collective struggles replaced by something more short-term, self-interested and individual? These questions are broad and by no means original. Scholars of new social movements from the 1970s onwards made connections between 'new forms of conflict and the emerging structure of postindustrial capitalism' (Melucci, 1985: 791). The changing nature of society in turn changed the nature of political action: 'Actors in conflicts are increasingly temporary' (p.797, original emphasis); 'they have a growing symbolic function' (p.797); movements exist as 'a network of small groups submerged in everyday life' (p.800); they 'practice in the present the change they are looking for' (p.801); and so on. More recently Micheletti (2003) and colleagues (Stolle et al., 2005; 
p. 150. Everyday consumption practices as a site for activism? Exploring the motivations of grassroots reuse groups

Micheletti and Stolle, 2007) have written extensively on the rise of what they term political consumerism, or using the market as an arena for political participation, drawing attention to a complex interplay of individual and collective acts in working towards change.

In my own research I have chosen to continue this line of enquiry, exploring everyday acts of consumption as a potential site for political participation, but my focus is on forms of consumption that occur in some way outside of the mainstream economy. Whereas market-based forms of politically- or ethically-motivated consumption have been most prominent in the literature, for example buying Fair Trade or organic goods, or consumer boycotts of particular companies or products, relatively little attention has been paid to ethical and political dimensions of alternative consumption practices, especially reuse. My study begins to fill this gap by questioning the role that consuming differently can play in addressing negative consequences of the perceived transition to a consumer society, with particular emphasis on attempts to reduce waste. I intend to capture some of the tensions arising from seeking to challenge the dominant logic of the consumer society - a 'preoccupation with the endless acquisition of consumer goods and experiences' (Humphery, 2011: 42) - while using tactics that to some extent remain governed by that logic, through changing lifestyle choices and everyday consumption habits. Ultimately, informed by practice theories of social change and reproduction (Shove et al., 2012), the study aims to contribute further to understandings of the two-way relationship between individual, day-to-day acts of consumption and wider, established patterns of consuming in certain ways.

This paper presents findings from the opening stages of the research, investigating two aspects of how participants make sense of their own engagement in alternative consumption practices: the types of private and public concerns they see as prompting them to consume in certain ways, some resonating strongly with critical accounts of the consumer society; and their different understandings of the part that their individual acts of consumption play in achieving broader change. It is to two contrasting examples of such theories of change that I will now turn.

\section{Politics in the everyday}

In this section I will introduce two contrasting theoretical models of political participation in everyday life. The first, prefigurative approach is explicitly about ensuring the everyday details of political activity are consistent with movement aims, with the implication that structures, relationships and processes that clash with these principles are rejected. The second approach, political consumerism, uses existing, dominant means - the logic of the capitalist market - with the hope of changing it from the inside. Throughout the discussion run two related senses of the everyday: the ongoing, as opposed to the episodic; and the mundane or ordinary.

\section{Prefigurative politics}

Prefigurative forms of action are those that create, in the present, a small-scale version of a hoped-for future world, by building 'alternatives in the here and now' (Maeckelbergh, 2011: 3) and beginning to form 'the structure of the new society within the shell of the old' (IWW, 2011: 3; Graeber, 2011). ${ }^{2}$ Central to this is a concern with the details of daily life and ensuring they are consistent with the vision of the new society, embodying 'within the ongoing political practice of a movement ... those forms of social relations, decision-making, culture, and human experience that are the ultimate goal' (Boggs, 1977: 100, my emphasis). 
p. 151. Everyday consumption practices as a site for activism? Exploring the motivations of grassroots reuse groups

One way that prefigurative politics differs from other approaches to social change is in the relationship between means and ends. Franks (2003) distinguishes anarchist prefiguration from other revolutionary activity, which he criticises for being consequentialist: it is the extent to which an action furthers the revolutionary goal that determines whether or not it is a desirable action to take; the end justifies the means. Leninist interpretations of Marxism, for example, saw the seizure of state power as necessary to transforming society, permitting 'the utilization of capitalist methods to advance "socialist construction"' (Boggs, 1977: 101) and ultimately reproducing 'the essentials of capitalism, including hierarchy, commodity production, and alienated labor, in a new and more total form' (p.103). In prefigurative politics, by contrast, not only are the means 'as important as the goal' (Breines, 1980: 422), but the two are inextricably linked: 'the temporal distinction between the struggle in the present and a goal in the future' is removed; 'instead, the struggle and the goal, the real and the ideal, become one in the present' (Maeckelbergh, 2011: 4, original emphasis).

Another key difference is that prefiguration occurs in practice, in doing. Instead of developing a theoretical destination, establishing it as orthodoxy and meticulously planning a strategy for arriving at that destination, the prefigurative approach lends itself especially to movements with multiple goals that are not (yet) fixed and are open to deliberation. Practice is central to understandings of social change from the bottom up, of how awareness can be raised and how support for a movement might grow, understandings that tend to inform prefigurative action. It is fundamentally about experimenting with new technologies and processes, testing them out and demonstrating - not merely persuading or demanding, but 'actively setting up alternative structures so that people can experience for themselves' (Maeckelbergh, 2011: 16, original emphasis) - that another world is possible, that viable alternatives exist (Graeber, 2002; North, 2011; Portwood-Stacer, 2012).

Historically, the term prefigurative politics has most commonly been applied in reference to social movements' organisational structures and decision-making processes, specifically those that are non-hierarchical, decentralised and emphasise participatory democracy through consensus decision-making (Graeber, 2002). Boggs (1977), for example, traces the prefigurative tradition from nineteenth century anarchism to the workers' councils of the early twentieth century and beyond, while Breines (1980) focuses in detail on the American New Left in the 1960s. More recent analysis has highlighted the prefigurative elements of the alterglobalisation movement (Graeber, 2002; Maeckelbergh, 2011) and Occupy (Graeber, 2011; Juris, 2012), again drawing attention to their innovative structures and democratic processes. Commitment to a prefigurative approach also influences the types of action that movements engage in. Franks (2003) argues that prefiguration - means being reflective of ends - is a defining characteristic of anarchist direct action, setting it apart from other expressions of socialist politics. Such tactics are about neither 'seizing state power' nor appealing to governments for change, but about 'exposing, delegitimizing and dismantling mechanisms of rule while winning ever-larger spaces of autonomy from it' (Graeber, 2002: 68). Unlike protest, direct action means 'acting as if the existing structure of power does not even exist ... acting as if one is already free' (Graeber, 2011).

Alongside overtly or traditionally 'political' activity, prefigurative politics can also refer to more mundane practices, including ways of consuming, leisure and cultural activities, which seek to challenge the pervasiveness of, or experiment with alternatives to, present-day consumer capitalism, 'breaking down the division ... between everyday life and political activity' (Boggs, 1977: 104). For Boggs:

...the radicalism of the sixties brought a new political content to the prefigurative tradition. It affirmed the importance of generalizing the struggles for self- 
p. 152. Everyday consumption practices as a site for activism? Exploring the motivations of grassroots reuse groups

management beyond the point of production, to include all spheres of social life and all structures of domination. It sought to integrate personal and "lifestyle" issues into politics ... And it focused on a wider range of issues that confronted the social system as a whole: health care, culture, ecology, etc. (p.119)

Examples of prefigurative action, then, might include establishing or participating in alternative economic systems such as barter or gift economies (Williams, 1996; Nelson et al., 2007; Granger et al., 2010; Willer et al., 2012); critical approaches to food provision like veganism, 'freeganism', foraging and 'growing your own' (Clark, 2004; Shantz, 2005; Cherry, 2006; Edwards and Mercer, 2007; Gross, 2009; PortwoodStacer, 2012); or the Transition movement's approach to moving towards lower carbon futures, which 'rather than developing an oppositional politics ... emphasise the generation of new possibilities' (North, 2011: 1588). ${ }^{3}$ Taken to its extreme this conceptualisation of prefigurative politics ranges from:

the explicit and collective assertion of alternatives - including participation in cooperatives, worker-run enterprises, and democratic bodies of various sorts - to innumerable daily acts of quiet resistance to capitalist logic, which can be as mundane as reading a book in the park (Young and Schwartz, 2012: 221; see also Holloway, 2010).

\section{Political consumerism}

If prefigurative politics is about creating alternatives in parallel to dominant institutions, the logic of political consumerism - roughly equivalent to ethical consumption, as it is more commonly known in the UK (Clarke et al., 2007) - is to use existing structures, specifically the market, to achieve political aims. Political consumerism can be defined as 'consumer choice of producers and products based on political or ethical considerations, or both' (Stolle et al., 2005: 246, original emphasis) and 'with the goal of changing objectionable institutional or market practices' (Micheletti, 2003: 2). In common with prefigurative practice it 'seeks to embed altruistic, humanitarian, solidaristic and environmental commitments into the rhythms and routines of everyday life' (Clarke et al., 2007: 233). Political consumers may choose to withhold their custom from a particular company or product, in the case of a boycott, and/or actively support another company or product through their shopping choices (a 'buycott'). In line with the consumer society thesis, then, the market becomes a new arena for engagement in politics: political consumers 'circumvent traditional channels for political participation to address the market and companies directly' (Stolle et al., 2005: 251). Political consumerist acts are, on the face of it, 'less organized, less structured, and more transient than conventional political participation' (p.252), tending to be comparatively 'sporadic and individualized' (p.250).

However, while the emphasis is on a market model of change - the aggregate effect of many individual decisions is assumed to have an impact on how businesses behave - this only tells 'half the story' of political consumerism (Clarke et al., 2007: 241). To begin with, the changing of personal consumption habits is only one of a number of roles played by consumers. Micheletti and Stolle (2007) identify three other distinct roles, with specific reference to the anti-sweatshop movement. First, consumers might support traditional campaign organisations - for instance manufacturing workers' unions - responding to their calls for boycotts, backing public appeals and generally increasing the visibility and palatability of the movement. Second, groups of consumers may join together and work strategically as a 'spearhead force' of change, targeting actions to maximise effectiveness. This might mean acting as a pressure group speaking on behalf of fellow consumers, or becoming role models for 
p. 153. Everyday consumption practices as a site for activism? Exploring the motivations of grassroots reuse groups

others with similar concerns. Finally, at the most radical end of the spectrum, smaller groups of 'enlightened and reformed consumers' (p.168), for example the media organisation Adbusters, reappropriate and subvert the images of mainstream marketing and advertising to 'shake up' culture, aiming to change prevailing predispositions around consumption.

These three roles begin to move the focus beyond isolated acts of atomised individuals and draw attention to the continued importance of social movement organisations to political consumerism (Micheletti, 2003; Holzer, 2006; Clarke et al., 2007; Balsiger, 2010). Accounts of individual and 'spontaneous' action tend to neglect the role played by campaigns, defined as 'intentional and coordinated collective action and framing activities' (Balsiger, 2010: 312). Drawing on research into the Swiss branch of the Clean Clothes Campaign (CCC), an international network of, again, antisweatshop organisations, Balsiger argues that such campaigns influence which private consumption activities become reinterpreted as public and political issues and which ones do not. Organisations involved in political consumerist campaigns can be seen as 'claimsmakers', in competition with other claimsmakers to make and keep their particular issues public. ${ }^{4}$ In doing so, they produce and disseminate knowledge in various ways. CCC has an internationally standardised code of conduct that they demand corporations should adopt: to the extent that their claimsmaking is successful, they effectively set the rules for acceptable production practices. On a different front, they publish information booklets and an 'ethical shopping map' for prospective supporters, this time attempting to set the rules of how to consume in the right way.

In this section I have introduced two key theoretical approaches to understanding politics as embedded in everyday life, raising numerous questions for both my own empirical research and broader reflection. Most importantly for this paper, consideration of prefigurative and political consumerist approaches has brought to light two contrasting theories of how small-scale changes in mundane, day-to-day activity might bring about more noticeable change on a wider scale. Political consumerism is predicated on a market model, whereby individual transactions literally 'add up' to the sum of the parts: by withholding or creating demand for particular goods and services at the expense of others, consumers, on aggregate, put pressure on the providers of goods and services to change their behaviour in certain ways. Implicit here, incidentally, is an assumption that it is these private businesses that hold the real power to effect change. Prefigurative politics, meanwhile, is precisely about taking advantage of small pockets of power and freedom to experiment with alternative ways of doing things in parallel with, and despite, more dominant structures. These alternatives then, it is argued, function as working examples, demonstrating to others that change is possible, winning support from the ground up and gradually becoming more widespread.

The remainder of the paper will focus on my own empirical research, beginning to explore how these two models, distinct theoretically, are deployed in more subtle and at times overlapping ways in participants' own understandings of their engagement in alternative consumption practices. First I will outline the approach taken to the research, before going on to present some early findings and analysis.

\section{Research approach and methods}

In my own research I have chosen to narrow my focus to three reuse groups or practices, broadly defined:

1. Freecycle and Freegle: Freecycle is an Internet-based network of local groups that 'match people who have things they want to get rid of with 
p. 154. Everyday consumption practices as a site for activism? Exploring the motivations of grassroots reuse groups

people who can use them' (http://www.uk.freecycle.org/). Members sign up to their local group and post offers of, or requests for, free goods via an online message board and/or email list. Freegle (http://www.ilovefreegle.org/) operates in the same way, but is made up of ex-Freecycle groups that broke away from the US parent organisation in 2009.

2. Abundance: Local groups of volunteers collect fruit that would otherwise go unused, either growing wild in public spaces or in private gardens with owners' permission. It is then distributed, usually free or with a small fee to cover costs (e.g. when producing preserves and chutneys). Many of these groups are called Abundance, named after the original project which started in Sheffield in 2007. For the purposes of this paper I will include all such groups under this heading.

3. 'Skippers': Skipping, otherwise known as dumpster diving, bin diving, bin picking and so on, refers to the salvaging of discarded food and other waste goods from skips and supermarket bins for personal consumption. It is commonly associated with a wider lifestyle sometimes called 'freeganism', 'loosely characterised as an anti-consumerist movement, where the market economy is avoided where possible' and which 'involves taking goods that appear abandoned, without paying for them' (Thomas, 2010: 98-99).

While these three groups vary considerably in their aims (such that they have any), in their public visibility and in the way they are structured (or not structured), they were chosen because they have three important features in common. First, they all see value in certain items that others - society at large, the market, individuals - consider to be waste, and exist primarily to ensure that those items are put to good use, or continue to be used. Second, they all, in theory, constitute some form of gift economy, where neither money nor usually barter are allowed to feature in transactions. Third, they are all, ostensibly at least, grassroots, bottom-up initiatives, run (where applicable) by local volunteers and with minimal links to private companies, public authorities or large charities.

Evidence in this paper draws primarily on in-depth, semi-structured interviews with skippers, Abundance volunteers and members of Freecycle and Freegle. Most of the analysis is based on the first 10 interviews conducted, as presented in an earlier version of this paper (Foden, 2012). It has been updated slightly to be consistent with emerging findings from subsequent interviews. This was particularly relevant in discussion around the problem of 'landfill', as highlighted below. To date a total of 44 participants have been interviewed. Analysis is also informed by online surveys of, respectively, 4400 Freecycle members and 4608 Freegle members, resident across the UK. While I have attempted to include a mix of different people in the research, it is worth considering the extent to which my results are skewed towards certain sections of the population and this represents a challenge for further analysis of my empirical material. The survey, for example, shows that two-thirds of respondents were female and approximately 95 per cent identified as White British, White Irish or another White background, suggesting that - crudely speaking - 'white women' were perhaps overrepresented in the sample. It is not yet clear whether or not this accurately reflects the active membership of reuse groups. Interviews have also drawn attention to the fact that many participants are high in cultural capital, often educated to degree level or beyond, but not necessarily in economic capital. Again, further consideration is required as to whether this is a characteristic of people engaged in alternative 
p. 155. Everyday consumption practices as a site for activism? Exploring the motivations of grassroots reuse groups

consumption practices, or if it merely reflects the specific group of participants that have agreed to be involved in the research.

\section{Findings: why do participants engage in alternative consumption practices?}

In this section I present some initial analysis of empirical findings, focusing on participants' own understandings of why they engage in alternative consumption practices and, if applicable, what they hope to achieve through it. I will begin by considering their primary reasons or motivations for engaging, before going on to explore the deeper question of what difference they feel their actions might make, both to their own lives and beyond. Finally I will discuss participants' ambivalence as to whether consuming differently can be considered a political act.

\section{Motivations}

First, participants were asked to give their primary reasons for engaging in their respective reuse activities. These rationales varied considerably and frequently involved complex negotiations of complementary or, at times, seemingly contradictory motivations. Many participants articulated both self-interested and other-oriented explanations for the same actions. Experiences of choice and necessity were often interwoven, with 'no choice' situations (for instance, lack of money) often connected to earlier 'choices' (to work less).

Here I will concentrate on three frequently recurring themes: waste, community and fun.

\section{Reducing waste}

Unsurprisingly, research participants fairly consistently referred to 'waste' in explaining their primary motivations for engaging in alternative consumption practices centred on reuse. Of all survey respondents, 95 per cent said they use Freecycle or Freegle in order to 'cut down on waste'. Interviews paint a similar picture, for example:

I think for me waste was the number one. I think it is just seeing a whole lot of fruit lying on the ground [that] kind of annoys me ... At one of our meetings I did ask people what their motivation was. For everybody waste seemed to be the biggest thing. (Peter, Abundance group organiser)

While it might seem tautological to report that anti-waste groups are anti-waste, a great deal of complexity lies beneath this apparently straightforward rationale. For many participants, 'keeping things out of landfill' was of prime importance, referring to the physical amount of refuse produced and the dilemma of what to do with it. This sentiment directly echoes the stated aims of both Freecycle and Freegle. ${ }^{5}$ Beyond this, interviewees tended to frame the problem of waste in terms of the act of wasting or squandering valuable resources. This might mean space or time as much as physical materials. For instance, Glynn, who helps run a cooperative trading skills and services, felt 'a bit wrong' about a family member's holiday home sitting empty and wanted to see its potential realised: 'you know, it should be used all the time'. Even when discussing the material stuff of waste, such as the quantity of edible food found in a supermarket bin, the primary concern was still with something 'good' going unused: 
p. 156. Everyday consumption practices as a site for activism? Exploring the motivations of grassroots reuse groups

it seems wrong to me that that food should not be used to feed people ... l'd like to encourage as many people as possible to use that resource. (John, regular skipper and Freecycle user)

Within this view of waste as the squandering of valuable resources, participants differed in explaining why this is problematic, or conversely why reducing waste is positive. For most people this is linked to broadly environmental concerns: the overexploitation of the earth's resources and associated issues like climate change and peak oil. Most survey respondents (84 per cent) saw 'conserving the planet's resources' as a motivation for using Freecycle or Freegle. This highlights, then, a perceived connection between local, individual choices and global, in this case ecological, consequences. One participant raised a particular sense of responsibility towards future generations:

it's about the sort of world I want my own children to grow up in and the values I want them to have ... We're wearing and we walk and we drive around in the earth's resources and they're finite and it's important that we pass that on to our kids, because if we don't, you know, we're gonna end up in even more trouble than we're in now. (Karen, Abundance group organiser)

As well as connectedness with the planet and its future inhabitants, wasteful consumption habits in the affluent world were also seen as linked with existing global social inequalities:

I've come to really hate the unfairness of a world that actually is full of plenty: resources, skills, we've all got loads going for us. And yet we either squander it or just steal it, or hoard it, so that there's a huge imbalance. (John, regular skipper and Freecycle user)

For others, the idea that waste is somehow wrong is based less on its perceived consequences and more on a deeply held, even self-evident, moral obligation: to waste is wrong in itself. One participant, then, opposed wastefulness to two virtues: 'frugality' and 'economy' (Glynn, cooperative trader and Freecycle user). Another, quick to distance herself from any environmentalist motivations, attributed these deep-seated values to her upbringing:

I would say to you that I'm not a green person ... I would say that I have no idea about my carbon footprint because I haven't and I don't care, but I am not a wasteful person. I was brought up to not waste, to reuse if you could. (Sue, Abundance volunteer)

\section{Community and the local}

Many participants also made reference to some notion of being part of a 'community' as a major motivation. For John (regular skipper and Freecycle user), this was about cultivating mutual interdependence, about learning 'how to care for each other', explicitly in opposition to the individualised society that he felt he was living in. Ruth, an active member of her local Transition group and self-confessed 'eco-nut', saw this mutually supportive community model as a vital part of building local resilience for an anticipated time when there will be less availability of, and in turn less reliance on, fossil fuels:

I believe in what the Transition movement stands for, which is that we need to get more local, you know, we need to build our communities back up to being more 
p. 157. Everyday consumption practices as a site for activism? Exploring the motivations of grassroots reuse groups

resilient to when oil prices shoot up through the roof and things, and that we can support ourselves and people around us ... You need to get to know people to do that. You need to have a community. It's the communities that will survive. (Ruth, Abundance volunteer and Freegle moderator)

Other participants referred to the more immediate value in being involved with local community groups. Abundance, for example, was seen as a good opportunity for 'getting to know my area and getting to know people, bringing people together' (Peter, Abundance group organiser). Fruit picking sessions require people to work together as a team, with 'a few people holding [a tarpaulin] up and then someone shaking the tree' (Emma, regular skipper and Abundance volunteer), enhancing the sociable nature of the activity and fostering, at least in the very short term, a degree of dependence upon each other.

\section{Fun}

Another commonly cited reason for engagement, alongside more 'serious' social and environmental concerns, was fun and conviviality, closely related to the sense of different people being brought together around these alternative consumption practices. Reclaiming food from supermarket bins was seen as an exciting experience as much as a functional one, heightened by the expectation and suspense of what might be found:

Partly it was a fun thing, and just seeing what you could get. Kind of like when you go charity shop shopping and you get something that no-one else has got. (Carla, regular skipper and Abundance volunteer)

Being outside, in pleasant surroundings and feeling more connected to where food comes from were important aspects of enjoying fruit collecting as part of Abundance:

Yeah there's also just satisfaction, you know, being outside ... usually it's nice weather at that time of year, you can be in a really nice garden. So that's quite enjoyable. (Peter, Abundance group organiser)

You know, it was summer, I was picking apples. It was lovely. Beautiful gardens generally, you know, really nice gardens. Yeah, it was just really good fun. (Sue, Abundance volunteer)

One participant linked her enjoyment of fruit picking sessions to a relative freedom from the rules which govern other spheres of life: 'there was no health and safety certificates and it was just people having a good time' (Sue, Abundance volunteer). Interestingly, this freedom was attributed to an informal, bottom-up way of organising, compared with the rigidity and bureaucracy of larger, more traditional institutions: 'If it was a council thing I wouldn't have turned up. Too many boxes to tick' (Sue).

\section{Making a difference?}

Beyond these motivations, research participants were also asked to reflect on what they ultimately hoped their engagement in reuse activities would achieve, if anything, and how this would come about. In other words I was interested in the difference they thought it might make, either to their own lives or to some wider situation.

For many, the first priority was about being consistent, living a life in keeping with their personal sense of right and wrong, or at least moving gradually closer to that goal. 
p. 158. Everyday consumption practices as a site for activism? Exploring the motivations of grassroots reuse groups

This would result in a degree of satisfaction or fulfilment. It could be interpreted as an attempt to build a coherent sense of self, or a consistent narrative about their lives:

I don't want to be a hypocrite. I want to live by my values and I feel like I'm making steps towards that. (Carla, regular skipper and Abundance volunteer)

It's partly my integrity. So living with myself and feeling I'm doing the right thing. (Peter, Abundance group organiser)

Participants also mentioned getting personal fulfilment in another way. Their consumption practices and wider lifestyle choices freed up time to engage in activities considered more rewarding:

Life has been so much fuller because of the time you gain from not watching a television ... The less I have to pay, the less I have to work, the more time I have with the kids. (Karen, Abundance group organiser)

Liz (Freegle user) pointed out a two-way relationship between working less, which she saw as part of a conscious, positive decision to prioritise time over money, and her engagement in alternative consumption practices. On the one hand she had less disposable income and so acquired goods for free or bought them second hand, primarily as a practical and to some extent necessary effort to cut costs. On the other hand she felt she had much more free time to do the work of consuming outside the convenience of the mainstream economy: to hunt for bargains or to look for, wait for, request and collect items through Freegle.

Some participants also shared their views on how their individual actions could contribute to change beyond their own lives, beginning to articulate the theories of change outlined earlier in the paper. One school of thought was that by choosing not to buy products from particular companies, or proactively choosing other products for positive reasons, one is withdrawing or giving support for those organisations and their business practices, the aggregate effect of which will be noticed. As discussed earlier, this broad model of change can be described as political consumerism (Micheletti, 2003), or seeing the market as an arena for political participation and money spent (or not spent) as votes cast for or against a company or product. For example, Emma said she tries to avoid shopping in supermarkets because she doesn't agree with their business practices, including how they treat staff and how much waste they create. By not shopping there she feels she is refusing to give them her support and money. She actively chooses to 'support' local food shops and especially charity shops:

I feel like it's doubly good because you're using something which other people don't want, and then you're also not buying something new, which has had to be completely created. So it's like you're recycling something but then you're giving money to charity at the same time. (Emma, regular skipper and Abundance volunteer)

Another common, but different, theory of how change might come about was through awareness raising and influencing other people, especially close friends or family. In this formulation, the direct effect of the actual act of not buying something is secondary. What is important is increasing the support for the cause and ultimately changing the way society thinks from the bottom up:

I think you can only change the world little bit by little bit. And the best way to change it is from the bottom up, so that you radiate your thoughts and your ideas 
p. 159. Everyday consumption practices as a site for activism? Exploring the motivations of grassroots reuse groups

to other people and the best way of doing that is to get them involved in something. (Karen, Abundance group organiser)

I think it's around awareness raising. You can pick three and a half tonnes of fruit and it's not insignificant, but in the grander scheme of things it's a drop in the ocean and it's not gonna make a great deal of difference to food sovereignty or anything else. So the main impact I think we can have is by raising awareness. (Peter, Abundance group organiser)

These perspectives hinted at the prefigurative approach to social change introduced above. Similarly, another participant, dissatisfied in the past with criticising the status quo but having no better solutions to offer, saw his engagement in alternative consumption practices as a way of demonstrating that something different, something better, is possible. This, again, can be interpreted as an example of prefigurative politics, of living in a way consistent with a hoped-for future, in order to show that it can be done:

For me it's about working towards the presentation of a viable alternative ... when I was younger l'd be critical of certain things and people would say "so what's the alternative?" and I didn't have an answer. (Glynn, cooperative trader and Freecycle user)

\section{A site for activism?}

Ultimately, interview participants were ambivalent on the political nature of their engagement in alternative consumption practices and whether or not their mundane, everyday performances of reuse can be considered a site for activism. Many readily recognised what might be called a politics of consumption, tracing a chain of connection between their individual day-to-day acts and wider social or environmental issues. When asked directly some were themselves willing to label these connections as 'political', albeit hesitantly. As Emma (regular skipper and Abundance volunteer) put it, 'I think everything about the way that you choose to live, kind of, yeah, is political'. And, as shown above, some even articulated a broad theory of change as to how their actions could in some way impact those wider issues positively, tending to speak in terms similar to established concepts in the social movements literature, especially political consumerism and prefigurative politics.

However, the same participants were more hesitant to label their own acts of consumption as a form of activism:

I would never really think about it as ... a political act. (Emma, regular skipper and Abundance volunteer)

I don't see [it] as being an activist. This is what I believe is right and this is the way I want to live. (Karen, Abundance group organiser)

This suggests that while many were aware of and concerned about a perhaps incidental connectedness between private choices and public issues ('consumption is political'), it was a step further to see their own everyday consumption as intentional acts to address these issues. Alternatively, it is reasonable to see this reluctance as at least partly semantic, with the term 'political' carrying significant baggage:

I keep avoiding the word political ... I don't have a ... worldview, or a symbol. I couldn't even read you out my mission statement. (John, regular skipper and Freecycle user) 
p. 160. Everyday consumption practices as a site for activism? Exploring the motivations of grassroots reuse groups

Frequently, mention of politics in interviews would lead to a discussion of traditional political institutions and parties, with participants often keen to distance themselves from these associations.

\section{Discussion, conclusions and further questions}

This paper has introduced an ongoing research project on grassroots reuse groups, particularly focusing on their ethical and political dimensions. Analysis of interview material reveals some of the varied, complex and overlapping motivations for engaging in alternative consumption practices, as well as summarising different perspectives on what it is intended to achieve. Overall, the paper has shown evidence of an ambivalent relationship to the politics of consumption. While participants frequently saw their private consumption choices as inherently political, as intimately connected to wider social and environmental issues, many were reluctant to see their action in response to this - changing their engagement in consumption practices - as an act of political activism in its own right. In this final section I will briefly bring the discussion of findings back to the theoretical starting points of the paper, before setting out the key issues for further study.

First, participants clearly identified with critical accounts of the consumer society, or at least aspects of that body of critique. The broad problem of 'waste', a central concern of the literature on consumerism, was a major motivation for engagement in alternative consumption practices, in turn drawing attention to depletion of resources, environmental destruction and increasing material inequalities locally and globally. Similarly, some participants saw individualism, another defining feature of how Bauman and others have characterised the consumer society, as an entrenched problem and, in response to this, framed their involvement in reuse communities as part of re-learning to be more interdependent. Frequent references to fun, enjoyment, excitement and the satisfaction of needs and wants emphasise, though, that while they might be 'ethical' or 'political', these activities are still first and foremost about consumption, driven by aesthetic as well as moral considerations.

Second, the findings presented here begin to apply the theoretical concepts of prefigurative politics and political consumerism, but also to expose the messiness of their application in practice. Most participants played down the expectation that their actions would 'make a difference', but on reflection this impulse was often somewhere beneath the surface. Acts of reuse were typically primarily about meeting some need, getting something for free or giving something away conveniently, then they were about meeting that need in a way that participants felt was consistent with their values or principles, and finally it was sometimes also hoped that they would bring about some positive change in the long run. Two pitfalls should be avoided here: ascribing an unrealistic level of intentionality, as 'political consumerism' or 'prefigurative politics', to participants' actions on the one hand; or taking merely primary motivations on board and downplaying their role as potential political agents on the other. Furthermore, when the language of political consumerism and prefigurative politics was used, the two were not necessarily treated as distinct philosophies in the same way that my interpretation of the literature would suggest. Creating alternative systems of exchange was frequently seen simultaneously as withdrawing support for particular companies and products, communicating preferences via the market, and setting up parallel structures and mechanisms that demonstrated a viable alternative to the market.

The paper also raises crucial questions for further consideration. Reflecting on participants' own experiences, this study will go on to explore in much more depth how 
p. 161. Everyday consumption practices as a site for activism? Exploring the motivations of grassroots reuse groups

people come to engage in different consumption practices, to adopt apparently radical alternatives into their ordinary daily lives, and particularly the role played by social relations in this process. This will, in turn, feed into understandings of the extent to which prefigurative and political consumerist action, both essentially practice-based approaches, can effectively contribute to social change.

\section{Notes}

1 While the term 'reuse groups' is helpful as shorthand, it should be noted that: (a) in some cases the goods in question are being 'used' for the first time; and (b) not all participants would see themselves as part of a group.

2 Almost all cases in the literature on prefigurative politics reflect socialist, anarchist or environmentalist concerns. Visions of the future world are therefore typically postcapitalist, anti-authoritarian and/or low-carbon. These are, broadly speaking, the types of concerns reflected in my own research, although not always explicitly so. It is quite conceivable, however, that prefigurative approaches might also be used by groups with very different aims. See, for example, Franks (2003: 28-30) for a brief discussion of right wing prefigurative politics.

3 See Weissman (2006) for an overview of many of these, and other, examples of prefigurative practices.

4 Micheletti and Stolle (2007: 165) report very similar findings in their own study of the anti-sweatshop movement: organisations were engaged in consciousness-raising, encouraging consumers 'to consider how their seemingly private consumer choice is connected to and, therefore, responsible for garment workers' labor rights and safety'. One of the movement's major successes has been, it is argued, in formulating the problem and making it easy to understand and well-known, especially evident in the commonplace use and understanding of the word 'sweatshop'.

5 In an earlier version of this paper (Foden, 2012) I reported that participants had tended not to cite the physical problem of waste as a major motivating factor. This finding was based on only the first 10 interviews, none specifically focusing on Freecycle and Freegle (although some participants had happened to be involved with these groups). As conjectured at the time, it is likely that this skew in participants accounted for the lack of references to reducing landfill.

* Correspondence address: Mike Foden, Centre for Regional Economic and Social Research, Sheffield Hallam University, Howard Street, Sheffield, S1 1WB. Email: M.Foden@shu.ac.uk. 
p. 162. Everyday consumption practices as a site for activism? Exploring the motivations of grassroots reuse groups

\section{References}

Balsiger, P. (2010) Making Political Consumers: The Tactical Action Repertoire of a Campaign for Clean Clothes. Social Movement Studies, 9, 3, 311-329.

Bauman, Z. (2000) Liquid Modernity. Cambridge: Polity Press.

Bauman, Z. (2005) Work, consumerism and the new poor, second edition. Maidenhead: Open University Press.

Bauman, Z. (2008) Does ethics have a chance in a world of consumers? Cambridge, Massachusetts: Harvard University Press.

Boggs, C. (1977) Marxism, prefigurative communism, and the problem of workers control. Radical America, 11, 6/12, 1, winter 1977-1978, 99-122.

Breines, W. (1980) Community and Organization: The New Left and Michels' "Iron Law". Social Problems, 27, 4, 419-429.

Cherry, E. (2006) Veganism as a Cultural Movement: A Relational Approach. Social Movement Studies, 5, 2, 155-170.

Clark, D. (2004) The Raw and the Rotten: Punk Cuisine. Ethnology, 43, 1, 19-31.

Clarke, D.B. (2003) The Consumer Society and the Postmodern City. London: Routledge.

Clarke, D.B., Doel, M.A. and Housiaux, K.M.L. (eds) (2003) The Consumption Reader. London: Routledge.

Clarke, N., Barnett, C., Cloke, P. and Malpass, A. (2007) Globalising the consumer: Doing politics in an ethical register. Political Geography, 26, 3, 231-249.

Edwards, F. and Mercer, D. (2007) Gleaning from Gluttony: an Australian youth subculture confronts the ethics of waste. Australian Geographer, 38, 3, 279-296.

Foden, M. (2012) Anti-consumerist activism? Exploring the motivations of grassroots reuse groups. Presented at Movements, Networks, Protest: New agendas for society and politics, King's College London, 15 June 2012.

Franks, B. (2003) The direct action ethic. Anarchist Studies, 11, 1, 13-41.

Graeber, D. (2002) The New Anarchists. New Left Review, 13, 61-73.

Graeber, D. (2011) Occupy Wall Street's anarchist roots [online], Al Jazeera, 30 November. Last accessed 5 October 2012 at: http://www.aljazeera.com/indepth/opinion/2011/11/2011112872835904508. html

Granger, R.C., Wringe, J. and Andrews, P. (2010) LETS as Alternative, Post-capitalist Economic Spaces? Learning Lessons from the Totnes "Acorn". Local Economy, 25, 7, 573-585.

Gross, J. (2009) Capitalism and Its Discontents: Back-to-the-Lander and Freegan Foodways in Rural Oregon. Food and Foodways, 17, 2, 57-79.

Holloway, J. (2010) Crack Capitalism. London: Pluto Press.

Holzer, B. (2006) Political consumerism between individual choice and collective action: social movements, role mobilization and signalling. International Journal of Consumer Studies, 30, 5, 405-415.

Humphery, K. (2011) The simple and the good: Ethical consumption as anticonsumerism, In: Lewis, T., and Potter, E. (eds.) Ethical Consumption: A critical introduction. London: Routledge: 40-53.

IWW (2011) Preamble, Constitution, \& General Bylaws of the Industrial Workers of the World [online]. Last accessed 5 October 2012 at: http://www.iww.org/PDF/Constitutions/CurrentlWWConstitution.pdf

Juris, J.S. (2012) Reflections on \#Occupy Everywhere: Social media, public space, and emerging logics of aggregation. American Ethnologist, 39, 2, 259-279.

Maeckelbergh, M. (2011) Doing is Believing: Prefiguration as Strategic Practice in the Alterglobalization Movement. Social Movement Studies, 10, 1, 1-20. 
p. 163. Everyday consumption practices as a site for activism? Exploring the motivations of grassroots reuse groups

McKendrick, N. (1982) The Consumer Revolution of Eighteenth-century England, In: McKendrick, N., Brewer, J. and Plumb, J.H. (eds) The Birth of a Consumer Society: The Commercialization of Eighteenth-century England. London: Europa: 9-33.

Melucci, A. (1985) The Symbolic Challenge of Contemporary Movements. Social Research, 52, 4, 789-816.

Micheletti, M. (2003) Political virtue and shopping: individuals, consumerism, and collective action. New York: Palgrave Macmillan.

Micheletti, M. and Stolle, D. (2007) Mobilizing Consumers to Take Responsibility for Global Social Justice. The Annals of the American Academy of Political and Social Science, 611, 1, 157-175.

Nelson, M.R., Rademacher, M.A. and Paek, H-J. (2007) Downshifting Consumer = Upshifting Citizen? An Examination of a Local Freecycle Community. The Annals of the American Academy of Political and Social Science, 611, 1, 141-156.

North, P. (2011) The politics of climate activism in the UK: a social movement analysis. Environment and Planning A, 43, 7, 1581-1598.

Portwood-Stacer, L. (2012) Anti-consumption as tactical resistance: Anarchists, subculture, and activist strategy. Journal of Consumer Culture, 12, 1, 87-105.

Ritzer, G. and Slater, D. (2001) Editorial. Journal of Consumer Culture, 1, 1, 5-8.

Shantz, J. (2005) One Person's Garbage...Another Person's Treasure: Dumpster Diving, Freeganism, And Anarchy. VERB, 3, 1, 9-19.

Shove, E., Pantzar, M. and Watson, M. (2012) The Dynamics of Social Practice: Everyday Life and How it Changes. London: Sage.

Stolle, D., Hooghe, M. and Micheletti, M. (2005) Politics in the Supermarket: Political Consumerism as a Form of Political Participation. International Political Science Review, 26, 3, 245-269.

Thomas, S. (2010) Do freegans commit theft? Legal Studies, 30, 1, 98-125.

Weissman, A. (2006) The Revolution in Everyday Life, In: Best, S. and Nocella, A.J. (eds) Igniting a Revolution: Voices in Defense of the Earth. Edinburgh: AK Press.

Willer, R., Flynn, F.J. and Zak, S. (2012) Structure, Identity, and Solidarity: A Comparative Field Study of Generalized and Direct Exchange. Administrative Science Quarterly, 57, 1, 119-155.

Williams, C.C. (1996) The New Barter Economy: An Appraisal of Local Exchange and Trading Systems (LETS). Journal of Public Policy, 16, 1, 85-101.

Williams, C.C. (2003) Explaining informal and second-hand goods acquisition. International Journal of Sociology and Social Policy, 23, 12, 95-110.

Williams, C.C. and Paddock, C. (2003) Reconciling Economic and Cultural Explanations for Participation in Alternative Consumption Spaces. Geografiska Annaler B, 85, 3, 137-148.

Williams, C.C. and Windebank, J. (2005) Why do households use alternative consumption practices? Some lessons from Leicester. Community, Work \& Family, 8, 3, 301-320.

Young, K. and Schwartz, M. (2012) Can prefigurative politics prevail? The implications for movement strategy in John Holloway's Crack Capitalism. Journal of Classical Sociology, 12, 2, 220-239. 